\title{
Improvement of flow capacity of the left internal thoracic artery graft assessed by using a pressure wire
}

\author{
Manabu Taniguchi, MD, ${ }^{a}$ Takashi Akasaka, MD, ${ }^{a}$ Yasuhiro Saito, MD, ${ }^{a}$ Shuichiro Kaji, MD, ${ }^{a}$ Takahiro Kawamoto, MD, \\ Renan Sukmawan, MD, ${ }^{a}$ Hidetoshi Yoshitani, MD, ${ }^{a}$ Yoji Neishi, MD, ${ }^{a}$ Tohru Ohe, MD, ${ }^{b}$ Kazuo Tanemoto, MD, ${ }^{c}$ \\ and Kiyoshi Yoshida, MDa
}

From the Divisions of Cardiology ${ }^{\mathrm{a}}$ and Cardiovascular Surgery, ${ }^{\mathrm{c}}$ Kawasaki Medical School, Kurashiki, Japan; and the Division of Cardiovascular Medicine, ${ }^{\text {b }}$ Okayama University Graduate School of Medicine and Dentistry, Okayama, Japan.

Received for publication Jan 5, 2007; revisions received April 11, 2007; accepted for publication May 11, 2007.

Address for reprints: Manabu Taniguchi, MD, 2-5-1 Shikata-Cho, Okayama 700-8558, Japan (E-mail: tmnb@md.okayama-u.ac.jp).

J Thorac Cardiovasc Surg 2007;134:1012-16 $0022-5223 / \$ 32.00$

Copyright $\odot 2007$ by The American Association for Thoracic Surgery

doi:10.1016/j.jtcvs.2007.05.049
Objective: We sought to evaluate improvement of flow capacity in a left internal thoracic artery graft by means of pressure measurement.

Methods: Eighteen patients who received a left internal thoracic artery graft to the left anterior descending coronary artery were studied. Angiography and pressure measurement at the proximal and distal portions of the left internal thoracic artery graft during maximal hyperemia with a pressure guide wire were performed at 1 month (early study) and 6 months (late study) after surgical intervention.

Results: There are no significant differences between the early and late studies in resting mean aortic pressure, left ventricular end-diastolic pressure, left ventricular ejection fraction, and percentage diameter stenosis of the recipient left anterior descending coronary artery. There was no stenosis in the anastomosis site of the left internal thoracic artery graft and the distal left anterior descending coronary artery, as determined by means of angiography, in the early and late studies. The mean diameter of the distal left internal thoracic artery graft was significantly increased in the late study $(1.6 \pm 0.2$ vs. $1.8 \pm 0.2 \mathrm{~mm}, P=.011)$. There was a significant difference between the early and late studies in the pressure gradient through the graft ( $15 \pm 4$ vs $13 \pm 3 \mathrm{~mm} \mathrm{Hg}, P=.036)$. The ratio of distal to proximal pressure within the left internal thoracic artery graft in the late study was significantly increased from that in the early study $(0.80 \pm 0.04$ to $0.84 \pm 0.03, P=.0003)$.

Conclusions: The pressure ratio within the left internal thoracic artery graft became higher as the left internal thoracic artery graft adapted itself to the myocardial circulation. This finding might relate to decreasing the resistance of the left internal thoracic artery graft.

I $\mathrm{n}$ the last 2 decades, there has been a trend toward use of arterial grafts instead of vein grafts for coronary artery bypass graft surgery because of longer patency rates and better long-term patient survival. ${ }^{1}$ Several angiographic studies of the left internal thoracic artery (LITA) graft have revealed that the LITA grows larger, remains unchanged, or diminishes in caliber. ${ }^{2-4}$ These responses result from vascular remodeling to achieve normalization of shear stress. ${ }^{5}$ Although a number of studies have shown these responses angiographically, it is known that angiography has some limitations. ${ }^{6,7}$ Therefore it is important to estimate the functional change of the LITA graft physiologically. Previous reports have demonstrated flow characteristics of the LITA graft by using a Doppler guide wire. ${ }^{8-10}$ This approach, however, has a possible influence on heart rate, preload, and contractility. ${ }^{11}$

Because the LITA graft is a long and narrow cylindrical conduit, the pressure at the distal portion of the LITA graft (Pd) should be less than that at the proximal portion $(\mathrm{Pp})$. In other words, the pressure decrease can be expected through 


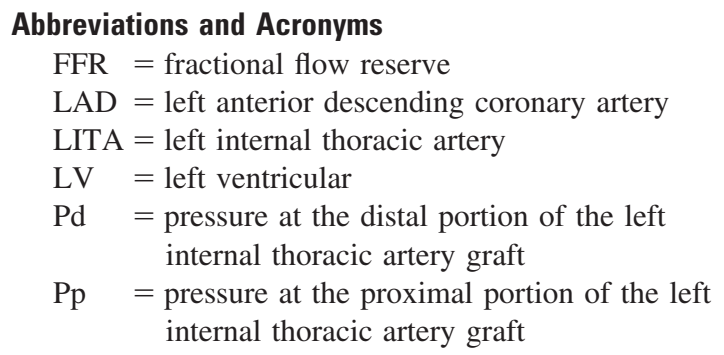

the graft. It is hypothesized that the remodeling of the LITA graft would be associated with reduction in the pressure gradient along the course of this conduit.

Accordingly, the purpose of the present study is to evaluate the remodeling of the LITA graft as a long cylindrical conduit by means of pressure measurement.

\section{Materials and Methods}

We examined 18 consecutive patients who had undergone elective coronary artery bypass grafting to the left anterior descending coronary artery (LAD) with a LITA graft and consented to the angiography and pressure examination at 1 month (early study) and 6 months (late study) postoperatively. Because the purpose of this study was to assess improvement of flow capacity of the LITA graft by means of pressure measurement, we used the following enrollment criteria: absence of a history of prior anterior myocardial infarction, absence of stenosis in the graft or the distal LAD, absence of the regression of stenosis ( $<75 \%$ stenosis) in the proximal native LAD, and absence of competitive flow from the other bypass graft anastomosed at the diagonal branch or left circumflex coronary artery to the LAD.

Graft patency was confirmed at the time of routine follow-up angiography. Patients who had collateral vessels from the LAD to the other coronary artery or from the other vessels to the LAD were excluded from this study. All patients provided written informed consent for this study. Cardiac catheterization, coronary angiography, and the subsequent pressure examination were performed as part of routine follow-up after bypass surgery.

\section{Cardiac Catheterization and Angiography}

Left heart catheterization was performed by using the femoral approach after local anesthesia with $0.5 \%$ lidocaine. Left heart pressure data were recorded by using a fluid-filled catheter-transducer system. Biplane left ventriculography was performed to assess the left ventricular (LV) wall motion and to measure LV volume by means of the area-length method. Selective coronary angiography was carried out by using the Judkins' technique after oral administration of $0.4 \mathrm{mg}$ of nitroglycerin. To assess the degree of the recipient $\mathrm{LAD}$ stenosis and to measure the diameter and area of the distal LITA graft corresponding to the tip of the pressure guide wire where the pressure of the distal LITA graft was recorded, coronary angiography was analyzed quantitatively by using an automated edge-detection method with a commercially available system (CMS, Medical Imaging System, Inc), according to previ-

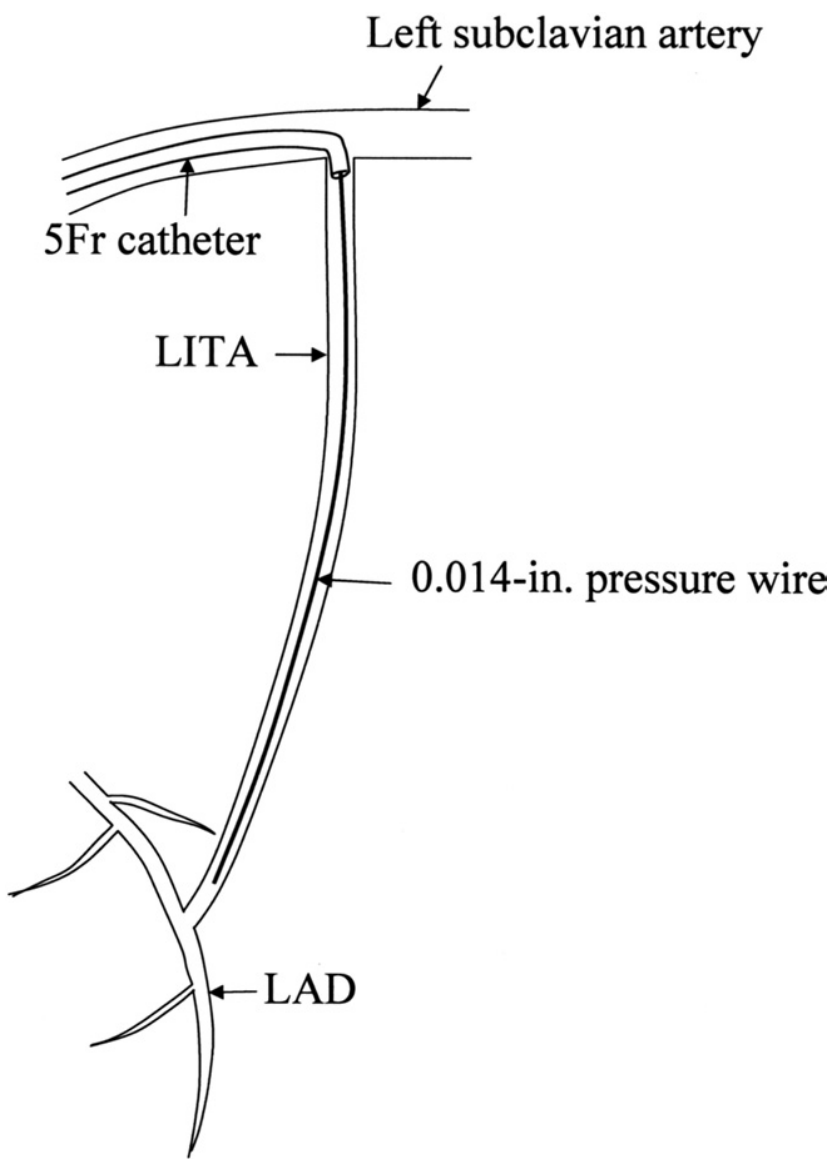

Figure 1. Methods for measuring pressure of the left internal thoracic artery (LITA) graft. LAD, Left anterior descending artery.

ous reports. ${ }^{12,13}$ Measurements of the distal LITA graft diameters were performed by 2 experienced observers, each blinded to the other's results.

\section{Pressure Recordings}

Pd was measured at the distal portion of the LITA graft by using a 0.014 -inch pressure guide wire inserted through the $5 \mathrm{~F}$ catheter. Pp was also monitored at the tip of the catheter by using a fluid-filled catheter-transducer system. Each pressure was recorded during hyperemia induced by intravenous adenosine $\left(0.14 \mathrm{mg} \cdot \mathrm{kg}^{-1} \cdot \min ^{-1}\right)$, and the ratio of distal to proximal mean pressure of the LITA graft $(\mathrm{Pd} / \mathrm{Pp})$ was calculated (Figures 1 and 2). Thus $\mathrm{Pd} / \mathrm{Pp}$ during maximum hyperemia is thought to be a similar index to the pressure-derived fractional flow reserve (FFR) calculated for coronary stenosis. ${ }^{14-16}$

\section{Statistical Analysis}

All data were expressed as mean values \pm standard deviation. Continuous variables were analyzed by means of the paired $t$ test. The relationship between pressure data of the early and late studies was assessed by means of linear regression analysis. Interobserver and intraobserver variability was calculated as the standard devi- 


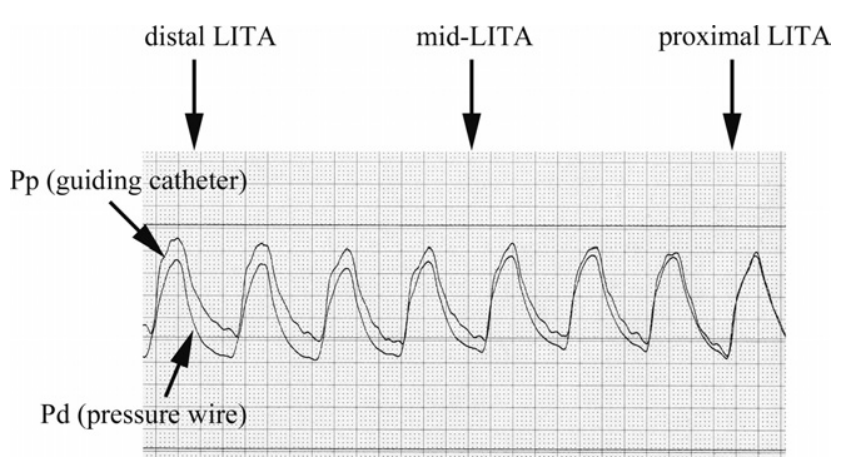

Figure 2. Pullback curve from the distal left internal thoracic artery (LITA) to the proximal LITA at the maximum hyperemia. Pp, Proximal LITA pressure; $\boldsymbol{P d}$, distal LITA pressure.

ation of the differences between the 2 measurements or assessments expressed as a percentage of the average value.

\section{Results}

\section{Clinical Characteristics and Cardiac Catheterization Data}

The clinical characteristics and cardiac catheterization data are listed in Table 1. The mean age of the patients included in this study was $68 \pm 9$ years. There are no significant differences between the early and late studies in resting mean aortic pressure, LV end-diastolic pressure, LV enddiastolic volume index, LV end-systolic volume index, LV ejection fraction, and percentage diameter stenosis of the recipient LAD. Heart rate in the early study was higher than that in the late study. Biplane left ventriculography showed no asynergy in the anteroapical portion of the left ventricle in any patient. There was no stenosis in the anastomosis site of the LITA graft and the distal LAD, as detected by means of angiography, in the early and late studies.

\section{Table 1. Cardiac catheterization data}

\begin{tabular}{llll}
\hline & Early study & Late study & $\boldsymbol{P}$ value \\
\hline Catheterization data & & & \\
$\quad$ Heart rate (beats/min) & $76 \pm 12$ & $68 \pm 14$ & .03 \\
Mean aortic pressure $(\mathrm{mm} \mathrm{Hg})$ & $86 \pm 13$ & $93 \pm 10$ & .06 \\
$\quad$ LVEDP (mm Hg) & $16 \pm 5$ & $17 \pm 7$ & .53 \\
Angiographic data & & & \\
LVEDVI (mL/m ${ }^{2}$ ) & $61 \pm 27$ & $68 \pm 28$ & .21 \\
LVESVI (mL/m²) & $18 \pm 14$ & $23 \pm 17$ & .06 \\
LVEF (\%) & $72 \pm 9$ & $70 \pm 9$ & .31 \\
\%DS of recipient LAD (\%) & $86 \pm 11$ & $90 \pm 11$ & .11 \\
Diameter of graft (mm) & $1.6 \pm 0.2$ & $1.8 \pm 0.2$ & .01 \\
\hline
\end{tabular}

$\angle V E D P$, Left ventricular end-diastolic pressure; $L V E D V I$, left ventricular end-diastolic volume index; LVESVI, left ventricular end-systolic volume index; $L V E F$, left ventricular ejection fraction; $\% D S$, percentage diameter stenosis.
Table 2. Pressure characteristics of the LITA graft

\begin{tabular}{lccc}
\hline & Early study & Late study & $\boldsymbol{P}$ value \\
\hline $\mathrm{Pp}(\mathrm{mm} \mathrm{Hg})$ & $76 \pm 12$ & $85 \pm 13$ & .01 \\
$\mathrm{Pd}(\mathrm{mm} \mathrm{Hg})$ & $61 \pm 10$ & $71 \pm 11$ & .001 \\
$\mathrm{Pp}-\mathrm{Pd}(\mathrm{mm} \mathrm{Hg})$ & $15 \pm 4$ & $13 \pm 3$ & .036 \\
$\mathrm{Pd} / \mathrm{Pp}$ & $0.80 \pm 0.04$ & $0.84 \pm 0.03$ & .0003 \\
\hline
\end{tabular}

LITA, Left internal thoracic artery; $P p$, proximal pressure of the left internal thoracic artery graft; $P d$, distal pressure of the left internal thoracic artery graft.

The mean length of the LITA graft was $119 \pm 20 \mathrm{~mm}$. There were significant differences in the LITA graft diameter and area between the early and late studies $(1.6 \pm 0.2$ vs $1.8 \pm 0.2 \mathrm{~mm}[P=.011]$ and $2.1 \pm 0.6$ vs $2.5 \pm 0.6 \mathrm{~cm}^{2}$ $[P=.014]$, respectively).

Interobserver and intraobserver variability of the diameter measurements in the distal LITA graft were $2.8 \%$ and $2.1 \%$, respectively.

\section{Pressure Characteristics of the LITA Graft}

The pressure characteristics of the LITA graft are listed in Table 2. There were significant differences between the early and late studies in $\mathrm{Pp}(76 \pm 12$ to $85 \pm 13 \mathrm{~mm} \mathrm{Hg}$, $P=.012), P d(61 \pm 10$ to $71 \pm 11 \mathrm{~mm} \mathrm{Hg}, P=.001)$, and $\mathrm{Pp}-\mathrm{Pd}(15 \pm 4$ to $13 \pm 3 \mathrm{~mm} \mathrm{Hg}, P=.036)$.

$\mathrm{Pd} / \mathrm{Pp}$ in the late study increased significantly compared with that in the early study $(0.80 \pm 0.04$ to $0.84 \pm 0.03$, $P=.0003$; Figure 3).

\section{Discussion}

The present study demonstrated that a pressure decrease can be demonstrated through the LITA graft, and $\mathrm{Pd} / \mathrm{Pp}$ within the LITA graft increased as the graft grew larger in size over time. To our knowledge, this is the first clinical follow-up

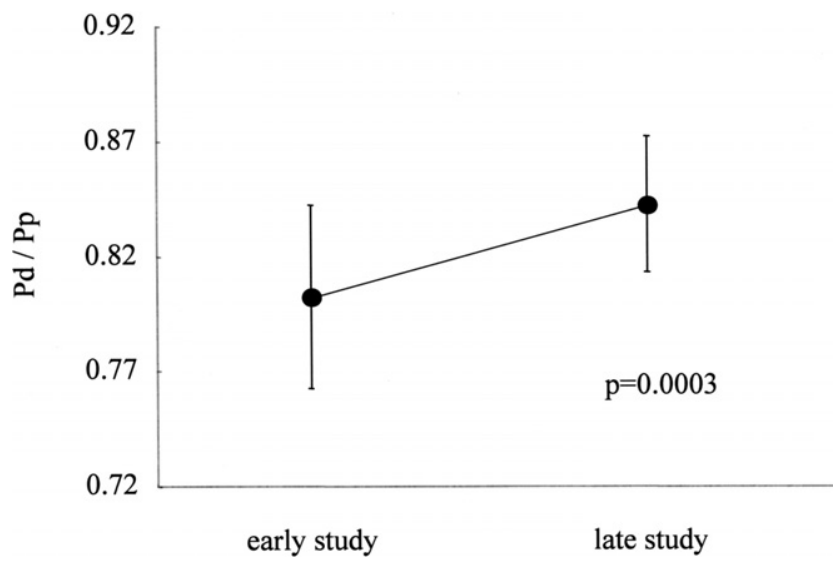

Figure 3. Changes in the ratio of the distal left internal thoracic artery pressure to the proximal left internal thoracic artery pressure $(P d / P p)$ between the early and late studies. 
study examining the pressure of internal thoracic artery grafts. Pd/Pp within the LITA graft can be a novel physiologic parameter in the analysis of coronary artery bypass graft function.

Previous studies with a Doppler guide wire, as well as angiography, have demonstrated that the internal thoracic artery graft grows larger over time, and its flow capacity improves late after surgical intervention. ${ }^{2-4,9,10,17,18}$ Although the remodeling of the LITA graft has been evaluated with angiography in numerous previous studies, angiography has some limitations. ${ }^{6,7}$ In cases with diffuse atherosclerosis without focal coronary stenosis, coronary angiography sometimes reveals a nonstenotic coronary artery; however, the coronary pressure and the FFR indicate abnormal epicardial coronary resistance. ${ }^{7}$ According to the study by De Bruyne and colleagues, ${ }^{7}$ a physiologic assessment, such as pressure measurement, might be more sensitive to detect the mild or diffuse diseases, which are difficult to diagnose visually. Thus the use of a physiologic measurement enhances the understanding of the LITA graft physiology. Moreover, the use of pullback pressure recording at maximum hyperemia from the distal to the proximal LITA graft might enable an additional functional assessment of diffuse stenosis within the LITA graft or an unexpected influence of bends or kinks or side branches, which are not uncommon with LITA grafts. ${ }^{19,20}$ Because LITA grafts alter their lumen diameter in response to chronic change in blood flow, the functional approach is necessary to assess the flow capacity of the LITA graft. In physiologic techniques, although the flow reserve obtained by using a Doppler guide wire depends on various hemodynamic conditions, such as heart rate, blood pressure, and LV contractility, $\mathrm{Pd} / \mathrm{Pp}$ measured with a pressure guide wire is reported to be independent from these factors. ${ }^{11}$ On the other hand, in cases with stenosis in the graft or the distal LAD, Pd might be influenced by the stenosis. ${ }^{19}$ Although these cases were excluded in the present study, the stenosis in the LITA graft or the distal LAD might be a limitation of the pressure method.

We demonstrated the pressure gradient through the LITA graft. Although there is no pressure gradient through an epicardial normal coronary artery, which is a long and narrow conduit, it has many side branches that connect to coronary microvessels. A previous study showed that coronary resistance was minimum during hyperemia because of a substantial redistribution of coronary microvascular resistance. ${ }^{21}$ Because the LITA graft is a long and narrow cylindrical conduit, the pressure decrease through the LITA graft can be expected if there is some flow. ${ }^{22}$ According to Poiseuille's equation, the pressure decrease across the LITA graft and the flow rate relate to the resistance of the LITA graft. This resistance has influence on the distal pressure of the LITA graft and the perfusion pressure over the myocardium supplied through the LITA graft. We found that $\mathrm{Pd} / \mathrm{Pp}$ was increased significantly in the late study. This finding indicates an increase in the myocardial perfusion pressure because of the decrease in the resistance of the LITA graft. The previous study concerning the flow reserve of the LITA graft with a Doppler guide wire also demonstrated that flow reserve early after the operation was significantly less than that assessed at 1 year postoperatively. ${ }^{9}$ In addition, radionuclide angiographic studies demonstrated that myocardial ischemia in the territories supplied by the LITA graft to the LAD was observed, even without the angiographic luminal stenosis. $^{23}$

Some limitations must be considered in the present study. First, we excluded the patients with stenosis in the LITA graft or the distal LAD, as determined by means of angiography, from this study. However, the patients with diffuse atherosclerosis in the distal LAD might demonstrate angiographically normal coronary values, although abnormal findings might be obtained physiologically. ${ }^{7}$

Second, microvascular disease might influence $\mathrm{Pd} / \mathrm{Pp}$, like FFR. ${ }^{20}$ The combined analysis of LITA flow velocity and pressure measurement might be needed to evaluate the influence of microvascular dysfunction on $\mathrm{Pd} / \mathrm{Pp}$.

Third, angiography was not performed during hyperemia in the present study. The diameter of the LITA graft should be measured at maximum hyperemia to compare the change of diameter with that of pressure accurately.

Fourth, the number of the patients in the present study was small. Further study of large numbers of patients should be done.

In conclusion, the $\mathrm{Pd} / \mathrm{Pp}$ ratio increased as the LITA graft adapted itself to the myocardial circulation. This finding might relate to decreasing the resistance of the LITA graft. Furthermore, it is demonstrated even if the increase in size of the LITA graft is trivial. Pressure measurement with a pressure guide wire can be a useful method in the assessment of LITA graft function.

\section{References}

1. Cameron A, Davis KB, Green G, Schaff HV. Coronary bypass surgery with internal-thoracic-artery grafts. Effects on survival over a 15-year period. N Engl J Med. 1996;334:216-9.

2. Seki T, Kitamura S, Kawachi K, Morita R, Kawata T, Mizuguchi K, et al. A quantitative study of postoperative luminal narrowing of the internal thoracic artery graft in coronary artery bypass surgery. $J$ Thorac Cardiovasc Surg. 1992;104:1532-8.

3. Nakayama Y, Sakata R, Ura M. Growth potential of left internal thoracic artery grafts: analysis of angiographic findings. Ann Thorac Surg. 2001;71:142-7.

4. Gaudino M, Alessandrini F, Nasso G, Bruno P, Manzoli A, Possati G. Severity of coronary artery stenosis at preoperative angiography and midterm mammary graft status. Ann Thorac Surg. 2002;74:119-21.

5. Barner HB. Remodeling of arterial conduits in coronary grafting. Ann Thorac Surg. 2002;73:1341-5.

6. White CW, Wright CB, Doty DB, Hiratza LF, Eastham CL, Harrison DG, et al. Does visual interpretation of the coronary arteriogram predict the physiologic importance of a coronary stenosis? $N$ Engl J Med. 1984;310:819-24. 
7. De Bruyne B, Hersbach F, Pijls NH, Bartunek J, Bech JW, Heyndrickx GR, et al. Abnormal epicardial coronary resistance in patients with diffuse atherosclerosis but "normal" coronary angiography. Circulation. 2001;104:2401-6.

8. Bach RG, Kern MJ, Donohue TJ, Aguirre FV, Caracciolo EA. Comparison of phasic blood flow velocity characteristics of arterial and venous coronary artery bypass conduits. Circulation. 1993;88:133-40.

9. Akasaka T, Yoshikawa J, Yoshida K, Maeda K, Hozumi T, Nasu M, et al. Flow capacity of internal mammary artery grafts: early restriction and later improvement assessed by Doppler guide wire. J Am Coll Cardiol. 1995;25:640-7.

10. Akasaka T, Yoshida K, Hozumi T, Takagi T, Kaji S, Kawamoto T, et al. Flow dynamics of angiographically no-flow patent internal mammary artery grafts. J Am Coll Cardiol. 1998;31:1049-56.

11. De Bruyne B, Bartunek J, Sys SU, Pijls NH, Heyndrickx GR, Wijns W. Simultaneous coronary pressure and flow velocity measurements in humans. Feasibility, reproducibility, and hemodynamic dependence of coronary flow velocity reserve, hyperemic flow versus pressure slope index, and fractional flow reserve. Circulation. 1996;94:1842-9.

12. Desmet W, De Scheerder I, Beatt K, Huehns T, Piessens J. In vivo comparison of different quantitative edge detection systems used for measuring coronary arterial diameters. Catheter Cardiovasc Diagn. 1995;34:72-80.

13. Hausleiter J, Nolte CW, Jost S, Wiese B, Sturm M, Lichtlen PR. Comparison of different quantitative coronary analysis systems: ARTREK, CAAS, and CMS. Catheter Cardiovasc Diagn. 1996;37:14-22.

14. Pijils NHJ, Bruyne B, Peels K, Van der Voort P, Bonnier JJRM, Bartunek J, et al. Measurement of fractional flow reserve to assess the functional severity of coronary artery stenosis. N Engl J Med. 1996; 334:1703-8.
15. Bartunek J, Sys SU, Heyndrickx GR, Pijls NH, De Bruyne B. Quantitative coronary angiography in predicting functional significance of stenoses in an unselected patient cohort. J Am Coll Cardiol. 1995;26: 328-34.

16. Pijls NH, De Bruyne B. Coronary pressure measurement and fractional flow reserve. Heart. 1998;80:539-42.

17. Kitamura S, Seki T, Kawachi K, Morita R, Kawata T, Mizuguchi K, et al. Excellent patency and growth potential of internal mammary artery grafts in pediatric coronary artery bypass surgery. New evidence for a "live" conduit. Circulation. 1988;78(suppl):I129-39.

18. Nasu M, Akasaka T, Okazaki T, Shinkai M, Fujiwara H, Sono J, et al. Postoperative flow characteristics of left internal thoracic artery grafts. Ann Thorac Surg. 1995;59:154-61.

19. Pijls NH, De Bruyne B, Bech GJ, Liistro F, Heyndrickx GR, Bonnier $\mathrm{HJ}$, et al. Coronary pressure measurement to assess the hemodynamic significance of serial stenoses within one coronary artery: validation in humans. Circulation. 2000;102:2371-7.

20. Pijls NH, Kern MJ, Yock PG, De Bruyne B. Practice and potential pitfalls of coronary pressure measurement. Catheter Cardiovasc Interv. 2000;49:1-16.

21. Chilian WM, Layne SM, Klausner EC, Eastham CL, Marcus ML. Redistribution of coronary microvascular resistance produced by dipyridamole. Am J Physiol Heart Circ Physiol. 1989;256:H383-90.

22. Mcdonald DA. Blood flow in arteries. London: Edward Arnold Press; 1974. p. 18-23.

23. Zafrir N, Madduri J, Mats I, Ben-Gal T, Solodky A, Assali A, et al. Discrepancy between myocardial ischemia and luminal stenosis in patients with left internal mammary artery grafting to left anterior descending coronary artery. J Nucl Cardiol. 2003;10:663-8.

To assure fairness to authors submitting work for consideration in The Journal of Thoracic and Cardiovascular Surgery, a mechanism exists for managing conflicts of interest. The editor and each of the section editors complete a "Conflict of Interest" form that identifies any and all relationships with commercial and other academic entities. When the editor has a potential conflict because of a relationship with another entity or author, the editor appoints an alternate editor from among the section editors or editorial board members who assumes the entire responsibility for final decisions on the manuscript in question. The editor does not read the reviews that are submitted nor engage in discussing the manuscript prior to the final decision. When the conflict of interest involves a section editor, a "guest section editor" is appointed who fills the role normally played by the conflicted section editor. All members of the editorial board and reviewers are asked to indicate any conflict of interest when they agree to review a manuscript. 